\title{
COMMUNITY INDICATOR FOR CARIES EXPERIENCE AMONG SCHOOLCHILDREN IN KUALA LUMPUR: AN ECOLOGICAL STUDY
}

M. Asma', R. Saub. Community indicator for caries experience among schoolchildren in Kuala Lumpur: An Ecological Study. Annal Dent Univ Malaya 2010; 17: $15-20$.

\begin{abstract}
The aim of the present study is to determine the "community indicator" for dental caries among secondary school children within the Federal Territory of Kuala Lumpur (FTKL). School factors were investigated for their ability to be used as community indicators. The components encompassing school factors include: type of school, school's examination performances at the Peperiksaan Menengah Rendah (PMR) level, in the subjects of Mathematics, Bahasa Melayu (Malay Language), Science and English, school's socioeconomic circumstances and school's material deprivation. The study design is ecological in nature where schools were the unit of analysis. It used aggregated data for caries experiences acquired from the Oral Health Management Information System and the school factors which were extracted from the schools' database. The subjects involved in this study were all the (75) day type secondary schools in FTKL. However, only 55 schools had complete information both for the dental caries factor and the school factors which were available for analysis. The use of bivariate analysis suggested that the school mean DMFT was significantly associated with the schools' performance in English $(p=0.02)$ and the schools' socioeconomic code $(p=0.005)$. The schools' performance in English and socioeconomic code were able to explain about 10 percent and 14 percent of the variation in the school mean DMFT respectively. The final model that included both variables together explained about 17 percent of the variation in school mean DMFT. As a conclusion, this study suggests that the schools' performance in English at the PMR level and the schools' socioeconomic code could be used as community indicator to identify secondary schools with higher caries level in FTKL. Nevertheless, further improvement of the model is needed in order to create a more reliable indicator.
\end{abstract}

Key words: caries, risk assessment, community indicator

\section{INTRODUCTION}

Dental caries is one of the country's public health problems. Although the prevalence of dental caries in most developed countries has decreased dramatically,
Original Article

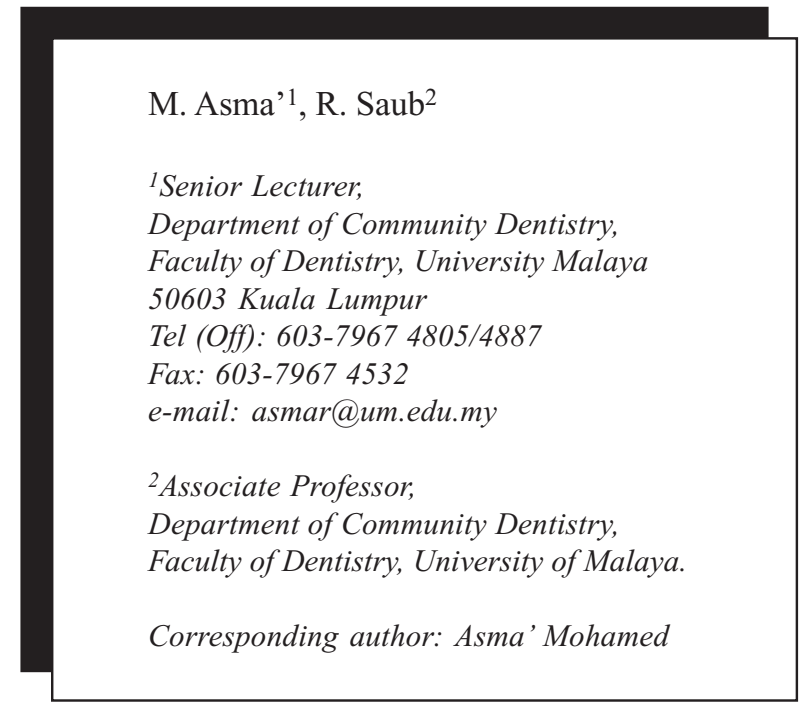

there are still, pockets of population, which suffers from it. A detailed analysis of caries prevalence in many of these developed countries often show polarization of such a disease $(1,2,3)$ whereby a skewed distribution of dental caries (4) prevails. This phenomenon has made some of the public health researchers to advocate a directed population strategy in preventing dental caries.

Risk assessment for dental caries can be performed at various levels: community, individual, tooth and tooth surfaces. The directed population strategy which is aimed at targeting the high-risk groups requires identifying the groups which are at risk. To do so, risk assessment is thus, performed at the community level. In this article, a "community" is defined as any group with common traits, shared features or communal experiences such as a city, state, school and military institution. Researchers have found that dental caries risk assessment models based on community (or area) was more feasible as compared to the individual model $(5,6,7,8)$.

Further, socioeconomic characteristics of the neighborhood were found to be better indicators of the health status of population subgroups than measures of the socioeconomic characteristics of individuals or households (9). In dentistry, socioeconomic characteristics of areas such as social deprivation index (10), Jarman deprivation score (11), Townsend index (12) are all classified as area-based measures (9) and these have been found to have a strong relationship with the area caries status and caries treatment needs.

Evidence from previous studies shows that educational indicators such as school performance $(13,14)$ and percentage completing primary level education at country level (15) were also good caries indicators for 5-year olds and 11-year olds in London 
and for 12-year olds in developing countries. Therefore, the use of area-based measures of social deprivation and education status as indicators of caries status is a possible choice. Nevertheless, the indicators will differ from one community to another community. In that regard, each community will need to identify its own indicator.

Epidemiological surveys of schoolchildren in Malaysia shows that there is a steady improvement of dental caries experience for 12 and 16-year old schoolchildren between 1971 - 1997 (16,17,18). It was also observed that caries distribution in FTKL was polarized where only $60 \%$ of 12 year-old schoolchildren were found to have carious teeth (18). The polarization of caries in FTKL can be expected to be more marked as compared to other parts of Malaysia because the prevalence and experience of caries in FTKL appeared to be the lowest. With the evidence of polarization of dental caries among schoolchildren, it is considered timely and appropriate to identify factors that can be used as community indicators in order to identify groups of schoolchildren with higher caries experience. With that, the aim of this ecological study was to identify model that could be used as community indicator for caries experience among secondary school children in the Federal Territory of Kuala Lumpur (FTKL).

\section{METHODS}

In this ecological study, schools in FTKL were identified as the unit of analysis. No sampling method was used and all schools that fulfilled the inclusion criteria were included in this study. The inclusion criteria composed of identifying schools which had form-four classes in the year 2004 and in that respect, had also conducted the PMR examination in the year 2003. Schools which were classified as special schools and technical schools were excluded from this study.

Two sets of data comprising i) caries experience and ii) school factors were collected. The data on caries experience were obtained from the Oral Health Management Information System (OHMIS). Caries experience was measured by using DMFT index. The school's mean DMFT was then calculated for each school.

The school factor variables included types of schools, schools' examination performance, schools' socioeconomic status and schools' material deprivation. This information was obtained from the schools' databases. The following describes the variables.

1. Types of school refer to schools which were i) single-gender schools if they catered to single gender schoolchildren and ii) co-ed schools when mixed gender schoolchildren were enrolled in the schools.
2. The schools' examination performance was measured based on the PMR examination results. Results were focused on four subjects used in the PMR examination: Mathematics (Math), Bahasa Melayu (BM), Science (Sc) and English (Eng). The percentage of schoolchildren who scored A (distinction) in each subject was calculated for each school.

3. Parental income of the form-four schoolchildren was also used as a measure of socioeconomic circumstance of the respective schools. The percentage of parents earning RM 2500 or less per-month was calculated for each school. The cut-off point was taken at RM 2500 because the average monthly household income for Malaysia in 1999 was RM 2472 (Eighth Malaysia Plan). The lower the percentage, the better the socioeconomic circumstance of the school.

4. The schools' material deprivation was measured based on the percentage of the formfour school children receiving textbook loans for each school. A higher percentage means high material deprivation status.

The Statistical Package for Social Sciences (SPSS) for window version 13 (SPSS Inc., Chicago) was used for the analysis of data. Data were entered directly into SPSS format. Data cleaning was done by manually checking (eye balling) for completeness after every 5 schools' data were entered. In addition, data cleaning was also done by running descriptive statistics such as frequency distribution and plotting graphs such as the boxplot.

The dependent variable for this study was the school DMFT and the independent variables were the schools factors. Descriptive analysis for continuous variables was done by calculating mean, standard deviation, minimum value, maximum value and quartiles. For variables which were not normally distributed, transformation was done. Categorization was done for variables where distribution could not be normalized by using transformation method. For categorical variables, frequency and percentages were calculated.

Bivariate analysis was done by using Independent student's t-test and simple linear regressions where appropriate. Multivariate analysis which uses multiple linear regressions (enter method) was then performed. The variables that were found to be significant in the bivariate analysis were entered into the model. The significant level was set at 0.05 . This study was approved by the Medical Ethics Committee, University of Malaya. Code no: DF CO0507/0017(P) 


\section{RESULTS}

Based on the inclusion criteria, 75 schools were found to be eligible. Caries experience data was then obtained from all the 75 schools while only 55 (73.3\%) schools were able to provide the school factors data. Therefore, analysis was only performed on the 55 schools.

Table 1 and 2 present the descriptive statistics for the types of school, the schools' mean DMFT, schools' performance and schools' socioeconomic circumstances. The mean of the schools' mean DMFT

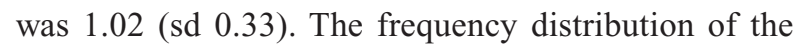
schools' mean DMFT and schools' material deprivation approximated normal distributions. Distribution of schools' performance (percentages of children scoring A in Mathematics, Bahasa Melayu, Science and English) appears not to follow the normal curve. Therefore, they were transformed by using logarithm to the base 10 .

Analysis also shows that schools' socioeconomic circumstance was not normal. It was then categorized into poor and good and was named as socioeconomic code. Poor socioeconomic code means that less than $50 \%$ of parental income were less than or equal to RM2500. About three quarters of the school were considered as having poor socioeconomic code.

Table 3 presents the summary of bivariate analysis (independent t-test and simple linear regression) of schools mean DMFT and all the school factors (type of school, school performance, schools' socioeconomic code and schools' material deprivation). The results of bivariate analysis show that schools mean DMFT was statistically associated with schools' socioeconomic code and schools' performance in English. The schools' socioeconomic code and schools' performance in English explained $14 \%$ and $10 \%$ variation in schools mean DMFT respectively.

The results of multiple linear regression analysis found that $17 \%$ of variations in the schools mean DMFT value can be explained by schools' socioeconomic code and $\log 10$ percentage of school children scoring A in English (Table 4). The interaction between the two variables were tested by using interaction terms and it was found to be non significant $[0.094$ (CI -1.023-0.082)]. The regression equation can be written as:

$$
\mathrm{Y}=1.081+\{-0.181(\mathrm{X} 1)\}+0.229(\mathrm{X} 2)
$$

Where $\mathrm{Y}=$ school mean DMFT

$$
\begin{aligned}
& \mathrm{X} 1=\log 10 \text { English } * \\
& \mathrm{X} 2=\text { socioeconomic code }
\end{aligned}
$$

\section{DISCUSSION}

The main aim of this study was to identify community indicators of dental caries which can be used to prioritize schools' dental programs among secondary schoolchildren in FTKL. However, the findings of this study must be interpreted with caution due to the limitations experienced in the study itself. The ecological study design requires data to be aggregated at school level. Therefore, the result from this study is only true at school level and inferences to individual level cannot be done.

The DMFT data was obtained from the OHMIS unit. This unit compiled data that have been collected by several dental officers working in the Dental Department of Kuala Lumpur. In that regard, the issue of standardization in terms of collecting the information may be raised. Although standardization and calibration of all the dental officers are not done every year, the process is done on a regular basis especially when new criteria for diagnosis are

Table 1. Frequency distribution of school by school type

\begin{tabular}{lcc}
\hline Type of school & $\mathrm{n}$ & $(\%)$ \\
\hline Single-ed school & 15 & 27 \\
Co-ed school & 40 & 73 \\
\hline Total & 55 & 100 \\
\hline $\mathrm{n}=$ number of school & &
\end{tabular}

\begin{tabular}{|c|c|c|c|c|c|c|}
\hline \multirow{2}{*}{ Variables } & \multirow{2}{*}{ Mean (SD) } & \multirow{2}{*}{$\begin{array}{l}\text { Minimum } \\
\text { value }\end{array}$} & \multicolumn{3}{|c|}{ Quartiles } & \multirow{2}{*}{$\begin{array}{l}\text { Maximum } \\
\text { value }\end{array}$} \\
\hline & & & 25 th & 50th & 75 th & \\
\hline School mean DMFT & $1.02(0.33)$ & 0.34 & 0.81 & 0.97 & 1.19 & 2.01 \\
\hline \multicolumn{7}{|l|}{ School Performance: } \\
\hline$\%$ score $\mathrm{A}$ in Math & $6.8(19.8)$ & 2.9 & 11.8 & 19.6 & 37.9 & 90.5 \\
\hline$\%$ score $\mathrm{A}$ in $\mathrm{BM}$ & $28.5(20.3)$ & 2.6 & 13.5 & 23.3 & 37.0 & 92.6 \\
\hline$\%$ score $\mathrm{A}$ in Science & $22.2(17.9)$ & 1.7 & 10.4 & 17.8 & 29.5 & 86.0 \\
\hline$\%$ score $A$ in English & $29.1(23.8)$ & 4.4 & 11.8 & 21.6 & 39.4 & 93.3 \\
\hline $\begin{array}{c}\text { School Socioeconomic circumstance: } \\
\% \text { parental income } \leq \text { RM } 2500\end{array}$ & $66.0(24.3)$ & 3.7 & 52.1 & 73.2 & 83.7 & 98.4 \\
\hline School Deprivation: & & & & & & \\
\hline$\%$ students receiving textbook loan & $47.0(22.0)$ & 3.7 & 26.7 & 45.7 & 63.0 & 94.4 \\
\hline
\end{tabular}

Table 2. Frequency distribution for mean DMFT for school, school performance, school socioeconomic circumstance and school material deprivation 
Table 3. Univariate analysis to determine associations of each school variable studied with caries

\begin{tabular}{|c|c|c|c|c|c|}
\hline Independent t-test & $\mathrm{n}$ & Mean (SE) & $\begin{array}{l}\text { Mean difference } \\
(95 \% \mathrm{Cl})\end{array}$ & $\begin{array}{l}\text { t-statistic } \\
\text { (df) }\end{array}$ & $p$-value \\
\hline Co-ed school & 40 & $1.03(0.05)$ & -0.05 & -0.464 & 0.645 \\
\hline Single-ed school & 15 & $0.98(0.09)$ & $(-0.25-0.16)$ & (53) & \\
\hline Simple linear regression & \multicolumn{2}{|c|}{$\begin{array}{l}\text { Unadjusted regression coefficient } \\
\qquad(95 \% \mathrm{Cl})\end{array}$} & \multicolumn{2}{|c|}{ Level of significance } & $\mathrm{R}^{2}$-value \\
\hline $\log _{10}$ Mathematics* & \multicolumn{3}{|c|}{$-0.019(-0.286-0.247)$} & 0.885 & 0.000 \\
\hline $\log _{10}$ Bahasa Malaysia* & \multicolumn{3}{|c|}{$-0.146(-0.427-0.136)$} & & 0.020 \\
\hline $\log _{10}$ Science $^{*}$ & \multicolumn{2}{|c|}{$-0.221(-0.478-0.036)$} & \multicolumn{2}{|c|}{0.09} & 0.053 \\
\hline $\log _{10}$ English* & & $4(-0.540--$ & \multicolumn{2}{|c|}{0.02} & 0.098 \\
\hline School socioeconomic code & \multicolumn{3}{|c|}{$0.291(0.092-0.490)$} & & 0.139 \\
\hline School material deprivation & & $2(-0.002-0$ & \multicolumn{2}{|c|}{0.325} & 0.018 \\
\hline
\end{tabular}

$\mathrm{n}=$ number of school

Dependent variable: School mean DMFT

Independent variable: Type of school, $\log _{10}{ }^{*}$ Mathematics, $\log _{10}{ }^{*}$ Bahasa Malaysia, $\log _{10}{ }^{*}$ Science and Log 10 *English, school socioeconomic ${ }^{*}$ school performance code, school material deprivation

Table 4. Multivariate analysis to determine the school variables as a community indicator for caries

\begin{tabular}{lccc}
\hline Multiple linear regression & $\begin{array}{c}\text { Unadjusted regression coefficient } \\
(95 \% \mathrm{Cl})\end{array}$ & $\begin{array}{l}\text { Level of significance } \\
\mathrm{R}^{2} \text {-value }\end{array}$ \\
\hline (Constant) & $1.081(0.633-1.529)$ & $<0.0001$ & 0.017 \\
Log $_{10}$ English & $-0.181(-0.442--0.079)$ & 0.013 & 0.170 \\
Socioeconomic code & $0.229(0.013-0.446)$ & \\
\hline $\begin{array}{l}\text { Dependent variable: School mean DMFT } \\
\text { Independent variable: Socioeconomic code, } \text { Log }_{10} \text { English }^{*}\end{array}$ & \\
${ }^{*}$ school performance &
\end{tabular}

introduced or when new officers report for duty. In addition, guidelines for oral healthcare for schoolchildren (19) which include a protocol for clinical examination and the recording of data is available. As such, it can be considered that the data collected, to a certain extent, is standardized. Furthermore, studies conducted in the United Kingdom found that general dental practitioners and previously trained dental examiners are in agreement with the total DMFT score (20).

The PMR examination is a compulsory examination taken by all form three schoolchildren. The examination papers were set by the Malaysian Examination Board and marking of the papers is done by several independent teachers. However, the marking process is standardized by the Malaysian Examination Board to ensure that the results are standardized.

This study found that schools' performance in English and schools' socioeconomic code can be used as indicators of dental caries among secondary school children in FTKL government schools.

The schools' socioeconomic code was found to be a good community indicator for caries. Schools with poor socioeconomic code were also found to have significantly higher mean DMFT. This finding concurs with previous studies which use Jarman (11) and Townsend (12) Indices as socioeconomic measures of an area to determine caries experiences. The Jarman scores were able to explain almost $10 \%$ of the variation in schools mean DMFT (11). Both indices were able to discriminate groups with different levels of treatment needs with strong correlation co-efficient $\mathrm{r}=0.89$ and $\mathrm{r}=0.88$ respectively $(11,12)$.

Many researchers found that performances in education can be used as an indicator of caries experiences $(14,15)$. The present study substantiates these findings. Out of the four subjects which were examined, only schools' performance in English was found to be significant. The relationship between schools' performance in English and schools mean DMFT score was inversely related. As the performance in English increases, so too does the schools mean DMFT improves. The equity of education in Malaysia could be used to explain the inability of the other subjects to predict caries status. The schools' performance in English is indirectly related to the educational and socioeconomic status of the parents who, are deemed to have a significant influence on the oral health status of the children. 
In conclusion, this study found that both the schools' socioeconomic code and performance in English were able to predict variation in schools mean DMFT. However, between the two, schools' socioeconomic code was the stronger indicator, explaining about $14 \%$ of the variation whereas schools' performance in English explained almost 10\% of the variation. Both variables were able to predict a variation of $17 \%$ in schools mean DMFT.

The result of this study suggests that schools' performance and schools' socioeconomic circumstances can be used as community indicators of caries status in secondary schools in order to identify secondary school students in FTKL who are at higher risk to caries. However, this model may need to be improved further so that a better percentage of prediction could be identified in order to help the Schools Dental Services in FTKL to further improve their use of scarce resources and to maximize oral health gains. It is also recommended that similar studies be done at state levels so as to identify appropriate school indicators or school risk indicators in order to help the manager at the state level to further improve their planning for incremental dental care programs. Each state should carry out its own study because indicators identified for an area cannot be used for other areas. For future studies, more school factors should be tested for their ability to explain variations in caries status. Hopefully, the indicators identified can explain the higher percentage variations seen in caries.

\section{ACKNOWLEDGEMENTS}

My sincere appreciation to Dr Husna Abbas, the Director of Oral Health Services, Wilayah Persekutuan Kuala Lumpur for granting me the access to data from OHMIS and her staffs for their cooperation in getting the data.

This study received financial support through University of Malay research vote: F0100/2005.

\section{REFERENCES}

1. Burt BA. Prevention policies in the light of the changed distribution of dental caries. Acta Odontol Scand 1998, 56: 179-86.

2. Kaste LM, Selwitz RH, Oldakowk RJ, Brunelle JA, Winn DM, Brown LJ. Coronal caries in the primary and permanent dentition of children and adolescencts 1-17 years of age: United States, 1988-91. J Dent Res 1996, (Spec Issue): 631-41.

3. Mosha HJ, Fejerskov O, Langebaek J, Thylstrup A, Baelum, V, Manji F. Caries experience in Urban Tanzanian children 1973-84. Scan J Dent Res 1998, 96: 385-9.
4. Peterson PE, Bourgeois D, Ogawa H, Estupian-Day $\mathrm{S}$, Ndiaye $\mathrm{C}$. The global burden of oral diseases and risk to oral health. Bulletin of the World Health Organisation. 2005, 83: 661-9.

5. Amstutz RD, Rozier RG. Community risk indicators for dental caries in schoolchildren: an ecologic study. Community Dent Oral Epidemiol 1995, 23: 129-37.

6. Mitropoulos C. The contrast in dental caries experience amongst children in the north west of England. Community Dental Health 1993, 10 (Suppl. 2): 9-18.

7. Taylor PJ, Carmichael CL. Dental health and the application of geographical methodology. Community Dent Oral Epidemiol 1980, 8: 117-22.

8. Gibson A, Gelbier S, Bhatia S. Dental health and treatment needs of five-year-old children in the health area of Lambeth, Southwark and Lewisham, England. Community Dent Oral Epidemiol 1981, 9: 5-9.

9. Locker D. Measuring social inequality in dental health services research: individual, household and area-based measures. Community Dental Health. 1993, 10: 139-50.

10. Gratrix D, Holloway PJ. Factors of deprivation associated with dental caries in young children. Community Dental Health 1994, 11: 66-70.

11. Ellwood RP, O'Mullane DM. Identification of areas with high levels of untreated dental caries. Community Dent Oral Epidemiol 1996, 24: 1-6.

12. Tickle M, Kay E, Worthington H, Blinkhorn A. Predicting population dental disease experience at a small area level using Census and health service data. Journal of Public Health Medicine 2000, $32: 368-74$.

13. Muirhead V, Marcenes W. An ecological study of caries experience, school performances and material deprivation in 5-year-old state primary school children. Community Dent Oral Epidemiol 2004, 32: 265-70.

14. Crowley E, O’Brien G, Marcenes W. School league tables: a new population based predictor of dental restorative treatment need. Community Dent Health 2003, 20: 78-82.

15. Egri M, Gunay O. Asssociation between some educational indicators and dental caries experience of 12-year-old children in developing countries: an ecological approach. Community Dent Health 2004, 21: 227-9. 
16. Dental Service Division, Ministry of Health. Dental epidemiological survey of school children in West Malaysian. Kuala Lumpur: Government printer 1972.

17. Dental Service Division, Ministry of Health. Dental epidemiological survey of school children in Peninsular Malaysia 1988. Kuala Lumpur: Government printer 1990.

18. Oral Health Division, Ministry of Health. Dental epidemiological survey of school children in Malaysia 1997. Kuala Lumpur: Government printer 1998.
19. Oral Health Division, Ministry of Health. Guidelines on oral healthcare for school children. Kuala Lumpur: Government printer 1996.

20. Nuttall NM, Claskson JE. Can dental epidemiological information be gathered during routine dental examinations by General Dental Practitioners? Community Dent Health. 2005, 22: 101-5. 